University of Montana

ScholarWorks at University of Montana

$2-2002$

\title{
Cost of Defense in the Context of Plant Competition: Brassica Rapa May Grow and Defend
}

\author{
David H. Siemens \\ Shannon H. Garner \\ Thomas Mitchell-Olds \\ Ragan M. Callaway \\ University of Montana - Missoula, Ray.Callaway@mso.umt.edu
}

Follow this and additional works at: https://scholarworks.umt.edu/biosci_pubs

Part of the Biology Commons

Let us know how access to this document benefits you.

\section{Recommended Citation}

Siemens, David H.; Garner, Shannon H.; Mitchell-Olds, Thomas; and Callaway, Ragan M., "Cost of Defense in the Context of Plant Competition: Brassica Rapa May Grow and Defend" (2002). Biological Sciences Faculty Publications. 313.

https://scholarworks.umt.edu/biosci_pubs/313

This Article is brought to you for free and open access by the Biological Sciences at ScholarWorks at University of Montana. It has been accepted for inclusion in Biological Sciences Faculty Publications by an authorized administrator of ScholarWorks at University of Montana. For more information, please contact scholarworks@mso.umt.edu. 


\title{
COST OF DEFENSE IN THE CONTEXT OF PLANT COMPETITION: BRASSICA RAPA MAY GROW AND DEFEND
}

\author{
David H. Siemens, ' Shannon H. Garner, Thomas Mitchell-Olds, ${ }^{2}$ and Ragan M. Callaway \\ Division of Biological Sciences, University of Montana, Missoula, Montana 59812 USA
}

\begin{abstract}
Theory on costs of plant defense against herbivory in stressful environments predicts that costs should increase when competition is intense. This amplifies a fundamental dilemma that plants are thought to face: allocate limited resources to grow fast enough to compete, or invest these resources in secondary metabolites to maintain defense. We studied costs associated with genetic and environmental variation in secondary metabolite production of Brassica rapa in the presence and absence of the generalist competitor Lolium perenne. We used experimental quantitative genetics (artificial selection) to manipulate genetic variation, and herbivore-induction treatments to produce environmental variation in myrosinase and glucosinolate concentrations and resistance. Glucosinolates, and their byproducts after breakdown by myrosinase, are known to affect herbivory on plants in the Brassicaceae family. Defense costs were significant in the absence of competitors, but in contrast to theoretical predictions, costs of constitutive defense (measured as growth rates) were not detectable and the cost of induced defense remained the same in the competitive environment. To understand what factors made constitutive defense costs not detectable under competition we conducted several experiments to assess the effects of limited resources and allelopathy on costs and benefits of the defense chemicals. None of the experiments involving nutrient supply and weak competition supported the hypothesis that the lack of defense costs in competitive environments was due to limited resources. Instead, the breakdown products of the glucosinolate-myrosinase reaction appeared to function as allelopathic agents, which may benefit $B$. rapa plants in competition, thereby reducing net costs of chemical defense. We found that: (1) the effects of exogenous glucosinolates on Lolium root length depended on the presence of myrosinase. (2) In the absence of nutrients, Lolium root lengths were shorter when seeds germinated with B. rapa. (3) Genetic increases in glucosinolate concentration negatively affected Lolium seedling growth only when there were simultaneous genetic increases in myrosinase concentration. Activated carbon treatments designed to neutralize allelopathic effects and restore costs in the competitive environments were, however, not statistically significant. When plant defenses also function to benefit plants in competitive interactions, plants may evolve to compete and defend.
\end{abstract}

Key words: allelopathy; artificial selection; Brassica rapa; constitutive defenses; costs of defense; herbivory; inducible defenses; interspecific competition; Lolium perenne; nutrient availability; plant stress; Plutella xylostella.

\section{INTRODUCTION}

A major goal of evolutionary ecology is to understand the factors that maintain genetic and environmental variation in traits important to interactions among species. Secondary plant metabolites are thought to play a central role in defense against herbivores, and even within populations there exists a great deal of genetic and environmental variation in the concentrations of particular secondary metabolites. Although higher concentrations of secondary metabolites might result in a more resistant plant, the production of secondary metabolites is thought to be costly (Simms 1992, Rausher 1996, Karban and Baldwin

Manuscript received 10 January 2001; accepted 21 February 2001; final version received 22 March 2001.

' Present address: University of Oregon, Eugene, Oregon 97403-1210 USA.E-mail: siemens@darkwing.uoregon.edu

2 Present address: Max Planck Institute of Chemical Ecology, Tatzendpromenade 1A, 07745 Jena, Germany.
1997, Harvell and Tollrian 1999, Stotz et al. 1999), and these costs that reduce plant growth and reproduction might maintain genetic variation within populations by preventing alleles that code for high levels of defense and maximum resistance from becoming fixed. Costs of defense have also been invoked to explain why many plants have evolved induced defenses, where concentrations generally increase only when plants are fed upon by herbivores, thereby producing a more economical defense-deployment mechanism (Harvell and Tollrian 1999). To test for the existence of costs of producing high concentrations of secondary metabolites, investigators have searched not only for costs associated with genetic variation in constitutive levels (Siemens and Mitchell-Olds 1998) but also costs associated with high induced levels of secondary metabolites (Baldwin 1998). Although some evidence indicates that defense costs exist, direct tests have often been negative despite the intuitive appeal of costs 
(Simms 1992, Bergelson and Purrington 1996, Rausher 1996, Karban and Baldwin 1997).

Discrepancies between theory and empirical studies on costs of defense may depend on the ecological context in which costs are measured. For example, it has been suggested that costs associated with defense production may become detectable under stressful conditions created by limited soil nutrients, water, or light (Bergelson and Purrington 1996). Stressful environments may increase costs in several ways. First, allocation of limited resources to maintain defense levels may decrease growth and other competing physiological processes in accordance with optimal allocation theory (McKey 1974, Rhoades 1979, Zangerl and Bazzaz 1992, Bazzaz and Grace 1997). Second, environmental stress can also cause concentrations of some secondary metabolites to increase (Gershenzon 1984, Waterman and Mole 1989) thereby increasing costs. However, one mechanism that has been invoked to explain these increases of secondary metabolites under stress suggests that costs might not also increase (Bryant et al. 1983, Herms and Mattson 1992). In this mechanism, limited resources are thought to directly inhibit the rate of growth and photosynthesis, but growth slows first so that fixed carbon from photosynthesis accumulates in excess of that required for growth. This excess of fixed carbon is then a cheap internal resource for defense production. Third, concentrations of defensive chemicals may increase during stress due to the release of active forms of defensive compounds from ruptured cells, causing autotoxicity. However, so few studies have actually measured costs of defense production in the context of environmental stress, the general theory that costs increase in stressful environments remains speculative (Bergelson and Purrington 1996).

Competition from other plants can create stressful environments, and if costs of defense should also increase under competition then this would amplify a fundamental trade-off that plants are thought to face: grow more rapidly than neighboring plants, or produce secondary metabolites for defense against herbivores and pathogens: the "grow or defend" paradigm articulated by Herms and Mattson (1992). However, if the production of defenses against herbivores also provides an added benefit in competitive interactions, then costs of defense should become less apparent in competition. For example, secondary metabolites with a general antibiotic effect have the potential to increase competitive ability by their allelopathic effects on neighboring plants (Williamson 1990, Inderjit and Del Moral 1997). Thus, although considering stress in studies on costs of defense is predicted to clarify the existence of these costs, plant competition may introduce other factors that might also influence costs.

Important secondary metabolites in brassicaceous plants include glucosinolates and their breakdown products produced by the action of myrosinase enzymes (Chew 1988). We used experimental quantitative genetics (artificial selection) and herbivore-induction treatments with diamondback moth larvae Plutella $x y$ lostella to study the consequences of constitutive and induced variation in glucosinolate and myrosinase levels in the presence and absence of a generalist competitor, the perennial rye grass Lolium perenne. Artificial selection allows investigators to study genetic variation in quantitative traits experimentally, as opposed to family structured analyses (Lewontin 1974, Simms and Rausher 1992), and we employed artificial selection experiments to study correlations that might cause evolutionary trade-offs or costs (Hill and Caballero 1992). When selection is directed at a single character, correlated evolutionary changes in another trait indicate the existence of genetic correlations between these traits (Falconer 1989). After a few generations of artificial selection, the existence of genetic correlations can be determined simply by testing for changes in the mean values of unselected traits. We have shown previously that artificial selection on constitutive concentrations of glucosinolates and myrosinase affects resistance to herbivores in ways predicted by insect physiology (Siemens and Mitchell-Olds 1996, 1998) and negatively affects maternal and paternal components of host-plant fecundity (Siemens and Mitchell-Olds 1998, Strauss et al. 1999). It has also been reported that artificial selection on glucosinolate content may affect the ability of plants to tolerate herbivory (Stowe 1998). In the present study we selected on constitutive glucosinolates and myrosinase levels simultaneously, which allowed us to study the combined and independent effects of genetic changes in the concentrations of these functionally related secondary metabolites. We have also shown previously that short feeding bouts by Plutella larvae on $B$. rapa induce higher levels of glucosinolates and myrosinase while causing minimal damage to plants (Siemens and Mitchell-Olds 1998). However, it should be noted that such induction treatments can cause many changes to secondary and primary metabolism in plants (Karban and Baldwin 1997), therefore in contrast to artificial section directed at particular metabolites, induction treatments do not control genetic background (Bergelson and Purrington 1996, Stotz et al. 1999). That is, any costs associated with induced variation in secondary metabolites might be caused by other unmeasured correlated physiological changes.

Specifically, in this study we asked the following questions: (1) Are costs of constitutive and induced production of secondary metabolites also manifest as reduced growth rates? Growth rate appears to be a particularly important component of fitness in the evolution of competitive interactions of Brassica plants (Miller 1995) and therefore should be measured when assessing trade-offs between defense and competition. (2) Do defense costs manifest as decreased growth rates increase when plants occur in the presence of nonhost neighboring plants in competitive situations? (3) Can 
the effects of neighboring nonhost plants on host defense costs also be produced by limited nutrient availability to host plants? (4) Do defense chemicals also have allelopathic benefits?

\section{Methods}

Costs of defense are inherently difficult to detect unambiguously because of the inherent difficulties involved in studying genetic and environmental variation in defense physiology. Defense costs are best evaluated in the absence of herbivores so that the benefits of resistance do not obscure measurement of costs, and when genetic backgrounds are controlled to minimize allelic differences between resistant and susceptible populations for genes affecting the fitness traits being measured (Bergelson and Purrington 1996, Purrington 2000). In the case of induction, plants should be induced with minimal damage to avoid costs that may be associated with wound responses and loss of photosynthetic area (Karban and Baldwin 1997:203). We used experimental organisms and techniques to satisfy all of these conditions.

\section{Experimental organisms}

Brassica rapa (syn. campestris) is an annual plant that grows in diverse naturalized weedy populations in North America, as well as cultivars in agriculture, and is fed upon by many insect herbivores. Brassica rapa has a self-incompatible breeding system, short generation times, and other attributes that make it well suited for artificial selection and experimental evolutionary ecology (Siemens and Mitchell-Olds 1998). Of the many insect herbivores that feed upon natural and agricultural populations of $B$. rapa (Thomas 1984, Lamb 1989), the most common at our sites in the Bitterroot Valley in western Montana is the flea beetle Phyllotreta cruciferae (Coleoptera: Chrysomelidae). Adult flea beetles feed mainly on seedling leaves by chewing small pits or holes $\sim 1 \mathrm{~mm}$ in diameter on leaf surfaces, which can significantly influence both seedling survivorship and numbers and masses of seeds produced by B. rapa (Pilson 1993). Herbivory by flea beetles can be accurately quantified by counting the number of pits per leaf and employing leaf size as a covariate. Another common herbivore of $B$. rapa is the diamondback moth Plutella xylostella, and on cultivars of $B$. rapa in agricultural plots infestation levels can be high (Harcourt 1957, Thomas 1984). Initial feeding by first instar larvae of $P$. xylostella occurs with minimal damage and induces levels of myrosinase, glucosinolates, and correlated resistance factors in the plant (Siemens and Mitchell-Olds 1996, 1998). We used larvae from a laboratory colony originally collected in Geneva, New York by A. Shelton in 1988 and maintained on artificial diet, which does not affect larval physiology even after several generations on the diet (Shelton et al. 1990). We used perennial rye grass Lolium perenne in experiments as a generalist competitor of $B$. rapa (e.g., War- dle et al. 1998). Lolium perenne ssp. multiflorum Lam. (ryegrass) is a widespread annual or biennial species that has been introduced from Europe. Lolium perenne is commonly used as a horticultural species and has naturalized in many of the same habitats as $B$. rapa throughout North America.

\section{Chemical assays}

Glucosinolates are low-molecular-mass nitrogen and sulfur containing compounds that are hydrolyzed by myrosinase (thioglucoside glucohydrolase, EC 3.2.3.1) producing D-glucose, sulfate, isothiocyanates (volatile mustard oils), and other compounds (Larsen 1981, Poulton and Moller 1993). Glucosinolates and myrosinase occur together throughout the plant but are separated cellularly, they and mix and react when pests damage cells (Chew 1988, Rask et al. 2000). Concentrations of glucosinolates vary with environmental factors such as nutrients (e.g., available soil nitrogen), water, light intensity, infection by pathogens, and feeding by insect herbivores (Wolfson 1982, Louda and Rodman 1983, Gershenzon 1984, Siemens and Mitchell-Olds 1996, 1998, Agrawal and Karban 1999).

Glucose from the breakdown of glucosinolates by myrosinase is easily quantified and total glucosinolate concentration or myrosinase activity can be inferred from glucose production. Rapid protocols for total glucosinolates or myrosinase concentration have been developed by Ian McGregor of Agriculture Canada and Thomas Mitchell-Olds for ease in handling the large sample sizes needed in quantitative genetic studies (Siemens and Mitchell-Olds 1998; see also Heaney and Fenwick 1981). Although correlative associations between chemical phenotypes and insect herbivory in field situations using these methods have been found (e.g., Siemens and Mitchell-Olds 1996, 1998), important effects of single defensive chemicals are probably masked (Berenbaum and Zangerl 1992). However, it should be noted that often some precision is compromised in quantifying relevant traits in experimental quantitative genetics, and that our attempts to quantify the physiological mechanisms associated with a relevant trait go further than many quantitative genetic studies.

Metabolite concentration or enzyme activity was divided by scanned leaf area for a measure of area-specific concentration. Although metabolite concentrations are generally reported per unit dry mass, recording leaf mass was not practical with the huge sample sizes and short time frame experienced in these quantitative genetic experiments. We have determined from previous greenhouse studies (D. H. Siemens, unpublished data) that wet leaf area is linearly correlated with both wet and dry leaf mass for both cotyledons (wet mass $=1.56+0.18$ (area), $r^{2}=69.1 \%, F_{1,59}=132.1$, $P<0.001$; mean dry mass [average of five leaves] $=$ $-0.29+7.82$ (mean area), $r^{2}=68.4 \%, F_{1,10}=21.68$, $P=0.001$ ) and true leaves (wet mass $=-0.013+$ 
0.11 (area), $r^{2}=92.8 \%, F_{1,59}=760.4, P<0.001$; mean dry mass $=0.28+4.60$ (mean area), $r^{2}=43.2 \%$, $F_{1,10}=7.60, P<0.02$ ).

\section{Genetically divergent lines from artificial selection}

We first developed populations or lines of $B$. rapa that were genetically divergent simultaneously in constitutive levels of myrosinase and glucosinolates as the result of two generations of artificial selection in the absence of herbivores. We started with seed collected in bulk from plants growing within a single wild population near Stevensville, Montana, with the goal of creating four lines representing all combinations of high and low myrosinase and glucosinolate levels. Our selection protocol minimized problems associated with random genetic drift, inadvertent selection, and linkage disequilibrium by implementing large sample sizes and a constant environment, and by using an outcrossing plant species (Siemens and Mitchell-Olds 1998).

We began the selection experiment by growing 500 seedlings from open-pollinated seeds originally collected in bulk from 45 plants growing at a single site. For each seedling, we then determined the leaf-areaspecific concentrations of myrosinase and glucosinolates in cotyledons because flea beetles attack these seedling leaves in the field. Plants were selected based on this leaf-area-specific concentrations, controlling for leaf area as a measure of developmental stage. However, hereafter we simply write "concentration" or "level" when referring to these developmentally adjusted area-specific concentrations. We controlled for leaf development because we knew that area-specific concentrations of these secondary metabolites decline with leaf size (Siemens and Mitchell-Olds 1998). This decline in concentration is a developmental phenomenon caused by secondary metabolite production increasing at a slower rate than leaf expansion and is not a statistical phenomenon caused by leaf size used in both our calculations of concentration and measures of leaf development. Comparisons of lines in experiments to evaluate costs were also controlled for development by using total leaf area, or leaf area from a single leaf (the same leaf on each plant) as a covariate in all statistical analyses. Another concern was the possibility that our selected differences in area-specific concentrations were partially caused by differences in leaf thickness because we did not control for leaf thickness in our selection experiments. However, we found no significant differences $\left(F_{3,8}=2.50, P>0.05\right)$ in leaf thickness as measured by leaf mass per unit area, among selected lines, but as a precaution, if data on leaf thickness were recorded in experiments, leaf thickness was also used as covariate in statistical analyses.

From the initial sample population of 500 seedlings, 48 plants were selected from each of the four lines to parent the next generation. However, before selecting these parent plants, we eliminated the extreme $5 \%$ of plants (three individuals) from the tails of each distri-

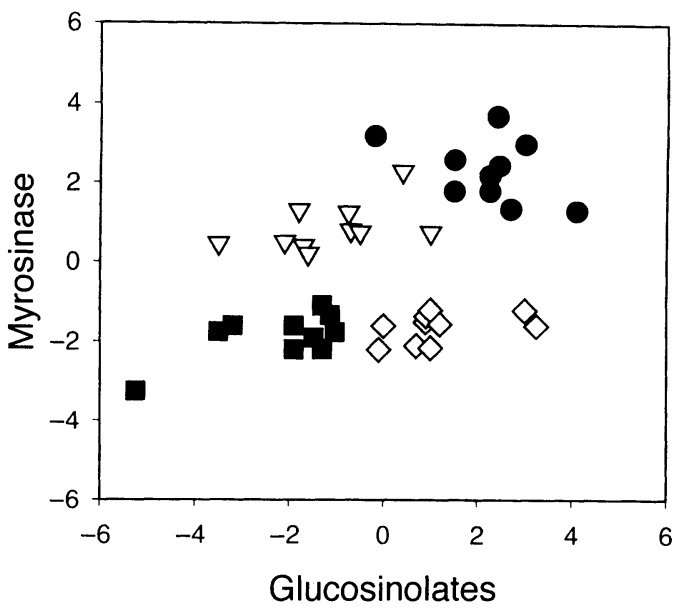

FIG. 1. Genetic changes in glucosinolate (G) and myrosinase (M) levels after two generations of artificial selection. Means of each maternal family are shown. Units are standardized values (zero mean and unit variance). Key to symbols: $M_{H} G_{H}$, filled circles; $M_{L} G_{L}$, filled squares; $M_{H} G_{L}$, open triangles; $M_{L} G_{H}$, open diamonds (where the subscripts $H$ and $\mathrm{L}$ denote lines selected for high and low levels, respectively).

bution to eliminate outliers that might cause spurious selection. For each line, the 48 selected plants were transplanted together and mass pollinated; pollen was transferred daily by hand using bee-sticks (thorax glued to a toothpick) among flowers within each line. We planted four seeds from each of the 48 selected plants (192 total seeds planted from each line) in a randomized design (768 total seeds) to start the next cycle of selection. We then selected 48 plants from each selected line as before to continue the selection process.

From each of the resulting lines, we only used seeds from plants (maternal families) that expressed the extremes for each trait in each selected line (Fig. 1) to enhance our ability to study independent functional effects of glucosinolates and myrosinase. For instance, from the line selected for high concentrations of both metabolites, we used seeds from the 10 families with the highest mean levels of both metabolites.

We also verified that the lines had indeed evolved to be differentially resistant to naturally occurring herbivores in a field experiment at the Western Montana Agricultural Research Station in Corvallis, Montana. In each of 20 blocks, one seed from each of the 10 maternal families within each of the four lines was planted $4 \mathrm{~cm}$ apart in a randomized design, with two additional border rows of nonexperimental seed to control for edge effects. From each seedling, we recorded herbivory by flea beetles (pit density) and leaf area, and we collected a leaf from each plant, which was oven dried to determine mass per unit area, a measure of leaf thickness.

\section{Do costs of defense increase under competition?}

We evaluated costs associated with high constitutive and induced levels of secondary metabolites in the 
presence and absence of an interspecific competitor. We used the lines that were selected for either high or low levels of both myrosinase and glucosinolates (i.e., $M_{H} G_{H}$ vs. $M_{L} G_{L}$ ) because these lines were the most divergent (Fig. 1); they allowed us to make the general comparison between high and low concentrations of defense metabolism, and they showed the greatest difference in resistance to flea beetles (see Results: Genetically divergent lines from artificial selection). However, this comparison did not allow us to differentiate between costs of producing myrosinase and costs of producing glucosinolates.

Before planting, we measured the diameter of each seed $( \pm 0.1 \mathrm{~mm})$ and used this measure as a covariate in the statistical analysis to avoid unmeasured effects on resistance (Bodnaryk and Lamb 1991). We planted one seed from each family randomly in each of 20 flats for a total of $400 \mathrm{~B}$. rapa seeds planted in this experiment ( 2 lines per flat $\times 10$ maternal families per line $\times 1$ seed per maternal family $\times 20$ flats $=400$ seeds ). Each flat consisted of a set of 20 separate $4 \times 4 \times 5$ $\mathrm{cm}$ wells for each seed and flats were kept consistently moist by placing them in a tray kept partially filled with water so that water was slowly wicked upward.

The two environmental factors, competition and herbivore induction, were varied at the whole-flat level. For the competition treatment, half of the flats were chosen randomly and planted with Lolium seeds. To ensure a strong competitive environment, two Lolium seeds were planted in each well $8 \mathrm{~d}$ previous to planting B. rapa seeds. For the herbivore-induction treatment, each of the plants within half of the flats of each competition treatment received a first instar larva of Plutella xylostella for $24 \mathrm{~h}$ starting on day seven after $B$. rapa seeds were planted. The 24 -h period was enough time for larvae to initiate mines of minimal area, $<1$ $\mathrm{mm}^{2}$, which was enough to induce defenses while minimizing effects on photosynthesis (leaf area eaten was consistently $0.02-0.05 \%$ of leaf area). The response variable in this experiment was the growth rate of $B$. rapa plants, computed as total leaf area per plant on day 7 subtracted from leaf area on day 15. Although plant biomass is a preferred measure of growth and fitness, we know that our measures of growth rate are correlated with total plant biomass $(r=56 \%$, Bartlett chi-square $=27.85, P<0.001, N=77$ plants) for $B$. rapa plants grown under these conditions in sandy soils with nutrient supplements where roots could easily be washed clean (data not shown). Moreover, for these short-lived plants that cycle from seed to seed in 6-8 wk, growth rates measured over a nine-day period, which are correlated with biomass, are important measures of plant fitness.

We used a split-plot experimental design, which maximizes statistical power in detecting interactions between within- and whole-flat factors (Snedecor and Cochran 1980). We were primarily interested in competition $\times$ line and competition $\times$ induction interac- tions, and while the competition $\times$ line interaction was between whole- and within-flat factors, the competition $x$ induction interaction was between two whole-flat factors for practical reasons. We did not choose to induce every other plant within flats to avoid larvae feeding on plants that were designated uninduced, thus there was slightly less statistical power to detect the competition $x$ induction interaction. However, because of the clear results, this uneven statistical power turned out to be a minimal concern.

\section{Do limited resources reduce defense costs?}

Limited resources in competitive environments may decrease exponential growth rates or decrease secondary metabolite production, thereby either decreasing the ability to detect defense costs or reducing the costs, respectively. We conducted an experiment to test whether limited resources differentially affected secondary metabolite production and defense costs among the genetically diverged lines. Statistically, we were interested in line $\times$ resource interactions in analysis of variance, and we used split-plot experimental designs again to maximize statistical power for detecting such interactions.

In this experiment, we recorded growth rates and secondary metabolite production for all four lines $\left(M_{H} G_{H}, M_{L} G_{L}, M_{H} G_{L}\right.$, and $\left.M_{L} G_{H}\right)$ grown under different nutrient concentrations. Ten seeds from each line were randomized in each of eight flats, for a total of 320 seeds planted. Flats consisted of forty $4 \times 4 \times 5 \mathrm{~cm}$ wells filled with silica sand and placed in trays that were kept partially filled with water. Each flat was assigned one of four hydroponics nutrient treatments, 1/ $4,1 / 8,1 / 16$, or $1 / 64$ strength Hoaglands administered once weekly, thus each nutrient treatment was replicated twice. Growth rates were measured as the difference in leaf width between days 7 and 15 after planting, and on day 16 we assayed leaves for concentrations of glucosinolates and myrosinase.

\section{Do allelopathic benefits reduce costs?}

Allelopathy is the toxic chemical influence of one plant on another resulting in effects similar to resource competition (Inderjit and Del Moral 1997). We examined the possibility that allelopathic benefits may have alleviated cosț of secondary metabolite production by conducting several experiments to test the potential allelopathic effects of glucosinolates and their breakdown products.

First, we assessed the allelopathic potential of these defensive compounds directly by testing the effects of sinigrin (a glucosinolate from Sinapis alba and Brassica species) alone and in combination with myrosinase (producing allylisothiocyanate) on growth of Lolium perenne. These chemicals were purchased from Sigma Chemical (St. Louis, Missouri, USA) and were not extracted from $B$. rapa; therefore we can only infer the potential for allelopathic effects of glucosinolates and 
myrosinase in $B$. rapa. Seedling root elongation (in millimeters) of Lolium was measured across a gradient of seven serially diluted (0.5) glucosinolate concentrations, starting at $1.0 \mathrm{mmol} / \mathrm{L}$, in three different treatments: (1) glucosinolates alone, (2) treatment 1 plus a constant concentration of myrosinase $(200 \mathrm{~mL}$ of $3 \mathrm{mg} /$ $\mathrm{mL}$ ), and (3) same as treatment 2 except heat-denatured myrosinase was added. All concentrations were within the range observed in plant tissues (Siemens and Mitchell-Olds 1998). For each treatment, we put 20 Lolium seeds in each of seven Petri dishes of $9 \mathrm{~cm}$ diameter and added enough treatment solution to cover seeds. After $1 \mathrm{wk}$, we computed the mean length of the five longest seedling roots, which represented maximum potential growth within a given concentration of a treatment.

Second, we tested allelopathic effects of seeds and germinating seedlings of both species by germinating seeds of each species alone or in an interspecific pair. Seeds were put in microplate wells with $0.5 \mathrm{~mL}$ water and no nutrients, and $1 \mathrm{wk}$ after germination initiated, we compared root lengths of both species. We began by using $B$. rapa seed from the original base population, then we conducted a similar experiment using a set of genetically diverged lines. In the experiment using seed from the base population, there were 200 replicates for each treatment for a total sample size of 600 replicates for this experiment. In the similar experiment we germinated Lolium seeds in the presence of 100 seeds from each $B$. rapa line $\left(\mathrm{M}_{\mathrm{H}} \mathrm{G}_{\mathrm{H}}, \mathrm{M}_{\mathrm{L}} \mathrm{G}_{\mathrm{L}}, \mathrm{M}_{\mathrm{H}} \mathrm{G}_{\mathrm{L}}\right.$, and $\mathrm{M}_{\mathrm{L}} \mathrm{G}_{\mathrm{H}}$ ), which allowed us to assess the separate and combined effects of genetic changes in the concentrations of glucosinolates and myrosinase on Lolium root lengths. These results using the seed from the diverged lines were then compared with results from the first allelopathic tests (preceding paragraph), in which we examined the effects of exogenous glucosinolates and myrosinase alone and together.

Third, we attempted to restore defense costs in a competitive environment by eliminating putative allelopathic benefits. We compared lines $\left(\mathrm{M}_{\mathrm{H}} \mathrm{G}_{\mathrm{H}}, \mathrm{M}_{\mathrm{L}} \mathrm{G}_{\mathrm{L}}\right.$, $M_{H} G_{L}$, and $M_{L} G_{H}$ ) growing in the presence of Lolium in two "soil" treatments: pure silica sand or silica sand mixed with finely ground activated carbon in a 1:50 carbon:sand ratio. Activated carbon adheres strongly to charged organic molecules that may be secreted from roots while having a minimal effect on ions such as plant nutrients and has been used to effectively reduce allelopathic effects for other species (Cheremisinoff and Ellerbusch 1978, Mahall and Callaway 1992). In other experiments (data not shown) we have not found any statistically significant effects of activated carbon in the concentrations used here on the performance of $B$. rapa. We used all of the lines to assess the separate and combined effects of the genetic changes in glucosinolates and myrosinase. We planted 10 seeds randomly from each of the 10 different families used previously from each line in each of 10 flats for a total of
400 total of $B$. rapa seeds planted (4 lines $\times 10$ seeds per family $\times 10$ flats). This design was also a splitplot experiment; half the flats at random contained the sand-carbon mixture, and within each flat were the selected lines. We recorded $B$. rapa leaf growth rate as total leaf area per plant on day 7 subtracted from leaf area on day 15 .

\section{Statistical analysis}

We used mixed model MANCOVA and ANCOVA to analyze the data from the experiments in this study. When multiple univariate analyses were performed on the data from a single experiment, we protected for Type I errors by first recording significance in a multivariate analysis (Barker and Barker 1984). To prevent further Type I errors in all analyses from considering multiple factors (e.g., line, environment, and the interaction between line and environment), we used sequential Bonferroni adjusted $P$ values (Rice 1989). We noted fixed and random effects and used appropriate mean square errors in computing $F$ ratios (Steel and Torrie 1980). We used SAS (1989) with Type III sums of squares for analyses. Cotyledon or true leaf area, leaf thickness, and diameter of seeds were included as covariates to control for developmental changes or other unmeasured correlated factors in metabolite concentrations. Although many of the experimental factors in our studies affect plant development, these factors have not significantly affected the general relationship between secondary metabolite level and development. Moreover, running the analyses with interaction terms for the covariates did not result in any significant interactions with main effects $(P$ values $>0.1)$, therefore these covariates do not appear in interaction terms in our analyses.

\section{RESULTS}

\section{Genetically divergent lines from artificial selection}

The response to two generations of selection indicated an axis of positive genetic covariation between myrosinase and glucosinolate levels. The base population was able to evolve toward low levels of myrosinase and glucosinolates or high levels of both metabolites, but less progress was made towards combinations of high and low levels of these metabolites (Fig. 1). Differences in the bivariate distribution of glucosinolate and myrosinase levels among selected lines in the third generation were statistically significant $\left(F_{6,614}\right.$ $=8.89, P<0.001$, by MANCOVA). Planned contrasts indicated that the selection resulted in significant differences in the levels of myrosinase $\left(F_{2,15}=21.77, P\right.$ $<0.001)$ and glucosinolates $\left(F_{2,15}=10.44, P=0.001\right)$. Because of the positive genetic correlation between the metabolites, our ability to study their separate effects was reduced. However, in our experiments we used seeds from maternal families in each selected line whose values were most diverged (Fig. 1), which en- 


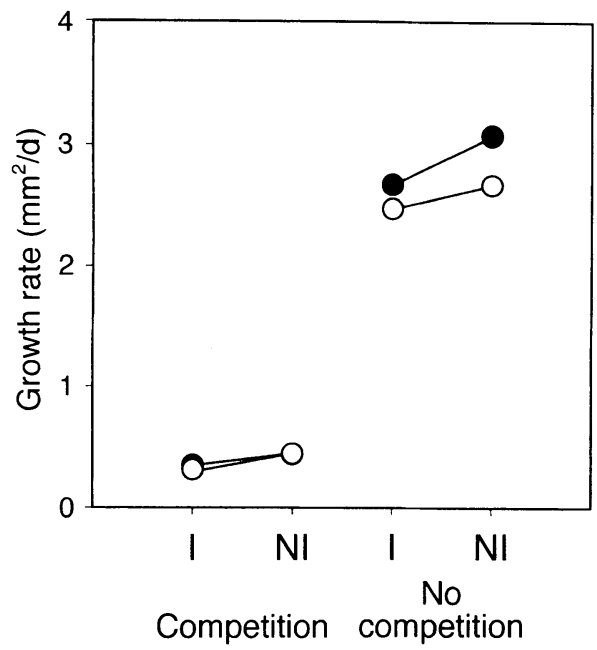

FIG. 2. Growth rates of the two Brassica rapa lines (Key to symbols: $\mathrm{M}_{\mathrm{H}} \mathrm{G}_{\mathrm{H}}$, open symbols; $\mathrm{M}_{\mathrm{L}} \mathrm{G}_{1}$, filled symbols) measured in competitive or noncompetitive environments. Onehalf of the plants of each line in each competition treatment were herbivore-induced (I), and the other half were not induced (NI). Standard error bars lie within each symbol. Analysis is in Table 1.

hanced our ability to detect the separate and interactive effects of myrosinase and glucosinolates.

Statistically significant heritabilities for myrosinase and glucosinolates were calculated previously (Mitchell-Olds et al. 1996, Siemens and Mitchell-Olds 1998) from artificial selection on each metabolite independently, starting from the same bulk seed collection using the same protocols and conditions. Heritabilities were calculated from parent-offspring regression between maternal parents in the base selected lines and the first generation of offspring (Falconer 1989): myrosinase $h^{2}=35 \%, F_{1,308}=20.95, P<0.001$; glucosinolates $h^{2}=17 \%, F_{1,208}=4.75, P=0.03$ ).

Genetic changes in glucosinolates and myrosinase resulting from artificial selection caused differences in resistance to herbivores in the field. High glucosinolate concentrations caused $14 \%$ more feeding by flea beetles $\left(F_{1,48}=11.17, P<0.01\right)$ in accordance with the physiology of specialist insects on Brassica plants (Siemens and Mitchell-Olds 1996). High myrosinase concentrations had the opposite effect and reduced feeding by flea beetles by $20 \%\left(F_{1,24}=10.15, P=0.004\right)$. The strongest and most clear effect was the difference between the lines selected for either high or low levels of both metabolites. The line selected for high levels of both metabolites was fed upon $25 \%$ more by flea beetles than the line selected for low levels (unprotected contrast: $F_{1,48}=10.76, P=0.002$ ). This counterintuitive effect was because high concentrations of glucosinolates result in susceptibility to specialists, even though they are agents of resistance against generalist insect herbivores (Chew 1988). Such conflicts in resistance to different herbivores may be common, but they do not influence the study of allocation costs associated with high concentrations of secondary metabolites (Berenbaum and Zangerl 1999).

\section{Do costs of defense increase under competition?}

We did not find any evidence for an increase in defense costs with increased competition; rather costs that were apparent in the absence of competition were not detectable in the competitive environment. When grown alone, the $\mathrm{M}_{\mathrm{H}} \mathrm{G}_{\mathrm{H}}$ (high myrosinase, high glucosinolates) line grew $13.3 \%$ slower than the $\mathrm{M}_{\mathrm{L}} \mathrm{G}_{\mathrm{L}}$ (low myrosinase, low glucosinolates) line; however, when individuals from $M_{H} G_{H}$ and $M_{L} G_{L}$ lines were grown with Lolium, growth rates did not differ (Fig. 2 ). This significant dependence of costs on competition treatment (Table 1: line $\times$ competition interaction, $P$ $=0.029$ ) indicates that constitutive defense costs did not increase and instead were not manifest in the competitive environment. Induction also reduced growth rates (Table 1: $P=0.029$ ), and this effect of induction was not influenced by competition (no competition $X$ induction interaction, $P=0.224$ ). Thus, while costs of constitutive defenses did not increase and were not detectable under competition, costs of induction did not change in the competitive environment.

\section{Do limited resources reduce defense costs?}

Reducing nutrient availability did not affect growth rates differently between the lines (Table 2: no interaction between line $\times$ nutrient concentration, $P>$ 0.05 ), even though there were significant main effects of line and nutrient concentration on growth rates. Nutrient limitation decreased growth rates by as much as $21 \%$, but there was no main effect of nutrient concentration on secondary metabolite production (Table 2);

TABLE 1. Comparison of growth rates between Brassica rapa selected lines and herbivore-induction treatments in the presence and absence of an interspecific competitor.

\begin{tabular}{llrrr}
\hline \hline \multicolumn{1}{c}{ Source } & df & \multicolumn{1}{c}{ MS } & \multicolumn{1}{c}{$F \dagger$} & \multicolumn{1}{c}{$P \ddagger$} \\
\hline Line & 1,16 & 120.03 & 17.80 & 0.003 \\
Environment & 3,16 & 2587.12 & 67.77 & $<0.001$ \\
$\quad$ Competition (Comp) & 1,16 & 7664.49 & 195.06 & $<0.001$ \\
$\quad$ Induction (Ind) & 1,16 & 226.92 & 5.78 & 0.029 \\
Comp $\times$ Ind & 1,16 & 62.92 & 1.60 & 0.224 \\
Line $\times$ Environment & 3,16 & 40.28 & 5.97 & 0.006 \\
$\quad$ Line $\times$ Comp & 1,8 & 104.33 & 7.07 & 0.029 \\
$\quad$ Line $\times$ Ind & 1,8 & 15.57 & 1.93 & 0.202 \\
Flat(Env) & 16 & 38.17 & 4.37 & $<0.001$ \\
Line $\times$ Flat(Env) & 16 & 6.74 & 0.73 & 1.000 \\
Leaf area & $2 \S$ & 344.69 & 39.46 & $<0.001$ \\
Seed size & $2 \S$ & 28.43 & 28.43 & 0.400 \\
Error & 292 & 2550.86 & & \\
\hline
\end{tabular}

Note: Flat(Env) is the variation among seed flats nested within the environment treatments (competition and induction).

$\dagger$ MS for $F$ ratios and corresponding df in split-plot design as specified in Steel and Torrie (1980).

$\ddagger$ Adjusted for Type I errors with sequential Bonferroni techniques (Rice 1989); $P<0.05$ is significant.

$\S$ Linear and quadratic terms combined; hence $2 \mathrm{df}$. 
TABLE 2. Effects of nutrient availability on growth rate and secondary metabolite production among the genetically diverged lines.

\begin{tabular}{lccc}
\hline \hline \multirow{2}{*}{ Source } & \multicolumn{3}{c}{$F$ ratio } \\
\cline { 2 - 4 } & Growth rate & $\begin{array}{c}\text { Myrosinase } \\
\text { concentration }\end{array}$ & $\begin{array}{c}\text { Glucosinolate } \\
\text { concentration }\end{array}$ \\
\hline Line & $4.44^{* *}$ & $3.34^{*}$ & $0.52^{* *}$ \\
Nutrient concentration & $3.15^{*}$ & 1.86 & 0.97 \\
Line $\times$ Nutrient concentration & 0.73 & 0.42 & 0.92 \\
Leaf area & $59.00^{* * *}$ & $19.29^{* * *}$ & $95.39^{* * *}$ \\
Seed size & 0.52 & 2.07 & 0.16 \\
Error df & 275 & 274 & 274 \\
\hline
\end{tabular}

* $P<0.05 ; * * P \leq 0.01 ; * * * P \leq 0.001$ (Bonferroni-adjusted $P$ values).

the genetic differences in defense production (Fig. 1) were maintained.

\section{Do allelopathic benefits obscure costs?}

In the presence of a constant concentration of myrosinase, root lengths of Lolium were shorter as exogenous glucosinolate concentrations increased (Fig. 3: $\left.r^{2}=0.97, F_{2.6}=84.80, P<0.001\right)$, suggesting that the breakdown products of the glucosinolate-myrosinase reaction function as allelopathic agents. We did not see this allelopathic effect with glucosinolates alone $\left(r^{2}\right.$ $\left.=0.26, F_{2.6}=1.04, P=0.409\right)$ or with glucosinolates plus denatured myrosinase $\left(r^{2}=0.27, F_{1,6}=2.210, P\right.$ $=0.188)$, although there was a slight allelopathic effect of myrosinase relative to the glucosinolate-alone treatment that was independent of glucosinolate concentration $\left(F_{1.18}=37.44, P<0.001\right)$.

The root lengths of both species were significantly shorter when seeds were germinated in the presence of

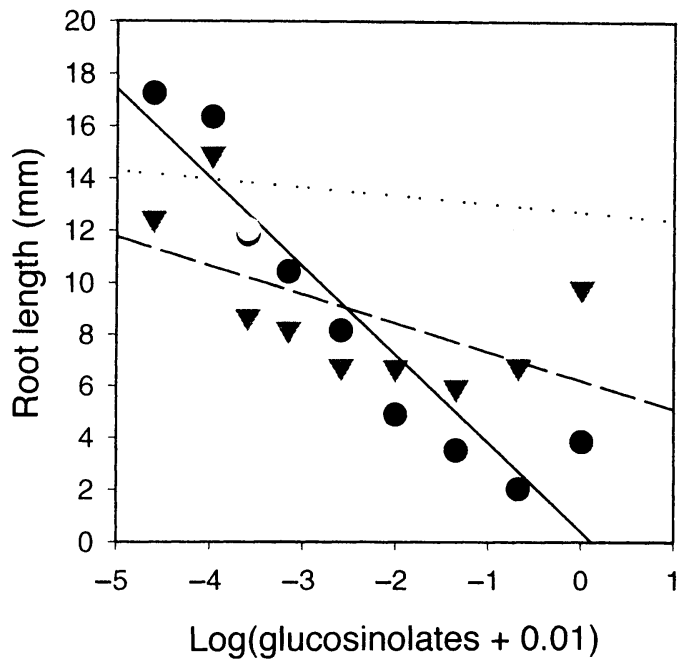

FIG. 3. Mean root elongation of Lolium perenne across a gradient of serially diluted $(0.5)$ glucosinolate concentrations starting at $1.0 \mathrm{mmol} / \mathrm{L}$. Key to symbols: glucosinolates alone (gray circles, dotted line), glucosinolates + constant concentration $(200 \mathrm{~mL}$ of $3 \mathrm{mg} / \mathrm{mL}$ ) of active myrosinase (black circles, solid line) or heat-denatured myrosinase (triangles, dashed line). The effect of glucosinolates depended on the presence of myrosinase. seeds from the other species, compared to when seeds were germinated alone (Fig. 4). The fact that there were no nutrients to compete for, and that these results were evident very early after seeds were germinated, indicates reciprocal allelopathic effects. Further evidence from germinating Lolium seeds with seeds from the $B$. rapa lines suggests that these allelopathic effects of $B$. rapa were caused by myrosinase-dependent effects of glucosinolates. Seeds from genetic lines with high concentrations of glucosinolates and myrosinase caused shorter root lengths of Lolium seedlings than seeds from lines with low concentrations (Table 3). Statistically, these allelopathic effects of genetic changes in glucosinolates that were dependent on simultaneous genetic changes in myrosinase are indicated by a significant glucosinolate $\times$ myrosinase interaction (Table 4 : $F_{1,235}=4.306, P=0.039$ ) as glucosinolate and myrosinase concentrations were determined for each seedling in each line. The independent effects of myrosinase and glucosinolates were not statistically significant (myrosinase: $F_{1,2.35}=2.190, P=0.140$; glucosinolates: $\left.F_{1,235}=0.328, P=0.567\right)$. Lolium root lengths in the presence of seeds from the line selected for high levels of both metabolites $\left(\mathrm{M}_{\mathrm{H}} \mathrm{G}_{\mathrm{H}}\right)$ were on average $8.7 \%$ shorter compared to growth in the presence of seeds from each of the other lines (Table 3). This result supports the previous contention that allelopathic effects of glucosinolates depend on the presence of myrosinase.

Although the activated carbon treatment appeared to restore costs in the competitive environment as predicted, these results were not statistically significant. Statistically, restored costs caused by activated carbon neutralizing allelopathic compounds would have been indicated in a line $\times$ carbon interaction in the ANOVA, but this interaction was not significant $(P=0.234$, Table 5). Except for the response of the $M_{H} G_{H}$ line in the activated carbon, all other responses of lines across carbon treatments were as expected. However, statistical significance was still not achieved after we excluded the $\mathrm{M}_{\mathrm{H}} \mathrm{G}_{\mathrm{H}}$ line from the analysis (line $\times$ carbon interaction: $F_{2,12}=2.173, P=0.146$ ).

\section{DisCUSSION}

Theoretically, costs of defense should increase in stressful environments (Bergelson and Purrington 
TABLE 3. Effects of germinating Lolium seeds in the presence of seeds from the Brassica rapa lines with water but no nutrients.

\begin{tabular}{lccc}
\hline \hline & & \multicolumn{2}{c}{ Brassica seedling concentrations $\ddagger$} \\
\cline { 3 - 4 } Line $\dagger$ & Lolium root length $(\mathrm{mm})$ & Myrosinase & Glucosinolates \\
\hline $\mathrm{M}_{\mathrm{H}} \mathrm{G}_{\mathrm{L}}$ & $5.12 \pm 1.120$ & $1.98 \pm 0.187$ & $0.92 \pm 0.068$ \\
$\mathrm{M}_{\mathrm{H}} \mathrm{G}_{\mathrm{H}}$ & $4.48 \pm 1.122$ & $2.87 \pm 0.192$ & $1.02 \pm 0.070$ \\
$\mathrm{M}_{\mathrm{L}} \mathrm{G}_{\mathrm{L}}$ & $5.21 \pm 1.121$ & $1.60 \pm 0.176$ & $0.89 \pm 0.064$ \\
$\mathrm{M}_{\mathrm{L}} \mathrm{G}_{\mathrm{H}}$ & $5.42 \pm 1.155$ & $2.03 \pm 0.188$ & $0.88 \pm 0.068$ \\
\hline
\end{tabular}

Note: Data are means \pm 1 SE. See Table 4 for statistical analysis of the effects of these functionally dependent secondary metabolites on Lolium growth.

$\dagger \mathrm{M}=$ myrosinase, $\mathrm{G}=$ glucosinolates, $\mathrm{H}=$ high, $\mathrm{L}=$ low; e.g., $\mathrm{M}_{\mathrm{H}} \mathrm{G}_{\mathrm{H}}$ is the line selected for high levels of both myrosinase and glucosinolates.

$\ddagger$ Developmentally adjusted leaf-area-specific concentrations $\left(0.17 \mathrm{mmol} \cdot \mathrm{L}^{-1} \cdot \mathrm{mm}^{-2}\right)$. Data are least-squares means from the regressions: concentration $=$ constant + leaf area + flat. Corrected concentrations were then multiplied by 100 .

1996), but we found that defense costs that were evident for $B$. rapa grown alone did not increase when $B$. rapa was grown in competition. Moreover, this theory does not distinguish between constitutive and induced levels of defenses in predictions regarding the effects of stress on costs; however, we found that the effect of competition on costs differed between constitutive and induced defenses. Costs of constitutive chemical defenses became undetectable in a stressful competitive environment, while costs associated with herbivore induction of secondary metabolites and resistance were not significantly affected by the same competitive environment (Fig. 2). Differences in costs between constitutive and induced defenses might be expected given the physiological differences between these defense deployment mechanisms, namely the signal transduction pathways associated with induction that involve phytohormones with multiple functions (Karban and Baldwin 1997, Kahl et al. 2000). However, the comparison of high constitutive and induced levels of secondary

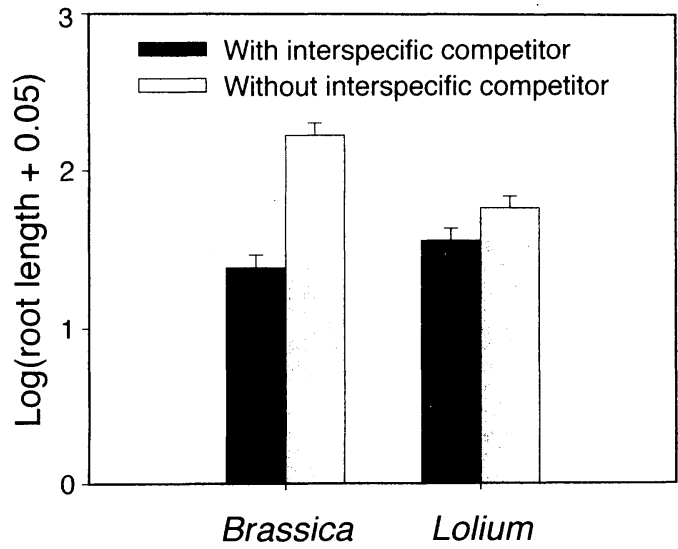

FIG. 4. Root length of germinating Brassica rapa seedlings alone (gray bar) or in the presence of a single germinating Lolium perenne seedling (black bar) ( $t$ test, $t_{1.205}=$ $7.27, P<0.001$ ), and root length of germinating Lolium perenne seedlings alone (gray bar) or in the presence of a single germinating Brassica rapa seedling (black bar) ( $t$ test, $\left.t_{1,180}=1.93, P=0.0276\right)$. Data show means +1 SE. metabolites with regard to costs is rarely made (but see Berenbaum and Zangerl 1999).

In their review on costs of plant resistance, Bergelson and Purrington (1996) reported only four studies that had considered effects of plant competition, and they found no discernible pattern between intra- or interspecific competition and costs of resistance in this small sample of studies. For instance, presence/absence of an interspecific competitor had no significant effect on costs of herbivore and disease resistance between near isogenic lines of lettuce Lactuca sativa (Bergelson $1994 a$ ), although costs were higher in nutrient-poor plots compared to fertilized plots. In another system, interspecific competition or nutrient shortage did increase costs of an herbicide resistance gene in Arabidopsis thaliana (Bergelson 1994b, Purrington and Bergelson 1997, Purrington and Bergelson 1999), and similar results were found for costs of a chloroplast gene encoding herbicide resistance in jimsonweed (Datura stramonium) evaluated in competition with maize (Williams et àl. 1995). In contrast, transgenic Arabidopsis that differed in the expression of an introduced antibiotic resistance gene did not exhibit costs even in nutrient-poor treatments (Bergelson et al. 1996, Purrington and Bergelson 1997). It is also not clear if the results of these studies can be extrapolated to more common polygenic resistance traits against herbivores involving secondary metabolism. Similarly, few stud-

TABLE 4. Effects of genetic changes in myrosinase and glucosinolate content in Brassica rapa on seedling growth of Lolium perenne.

\begin{tabular}{lrccc}
\hline \hline \multicolumn{1}{c}{ Source } & df & MS & $F$ & $P \dagger$ \\
\hline Myrosinase & 1 & 0.29 & 2.190 & 0.140 \\
Glucosinolates & 1 & 0.04 & 0.328 & 0.567 \\
Myr $\times$ Gluc & 1 & 0.57 & 4.306 & 0.039 \\
Flat & 9 & 0.14 & 1.048 & 0.403 \\
Area & 1 & 0.44 & 3.336 & 0.069 \\
Seed diam & 1 & 0.30 & 2.305 & 0.130 \\
Error & 235 & 0.13 & & \\
\hline
\end{tabular}

$\dagger$ Adjusted for Type I errors with sequential Bonferroni techniques (Rice 1989). 
TABLE 5. Effects of activated carbon on growth rate of the genetically diverged lines.

\begin{tabular}{lcrcc}
\hline \hline \multicolumn{1}{c}{ Source } & $\mathrm{df}$ & $\mathrm{MS}$ & $F \dagger$ & $P \ddagger$ \\
\hline Line & 3 & 1722.32 & 1.691 & 0.196 \\
Charcoal & 1 & 1495.88 & 0.496 & 0.504 \\
Line $\times$ char & 3 & 1549.69 & 1.522 & 0.234 \\
Flat(char) & 7 & 3017.87 & 3.567 & 0.002 \\
Line $\times$ flat(char) & 24 & 1018.45 & 1.204 & 0.251 \\
Seed diameter & $2 \S$ & 518.61 & 0.613 & 0.543 \\
Error & 129 & 846.00 & & \\
\hline
\end{tabular}

Note: Flat(char) is the variation among flats nested within the charcoal treatment.

$\dagger$ MS for $F$ ratios and corresponding df in split-plot design as specified in Steel and Torrie (1980).

$\ddagger$ Adjusted for Type I errors with sequential Bonferroni techniques (Rice 1989).

$\S$ Linear and quadratic terms combined; hence $2 \mathrm{df}$.

ies have been conducted on costs of induced defenses in the context of plant competition. Van Dam and Baldwin (1998) showed that fitness of wild tobacco plants (Nicotiana attenuata) induced with the wound-related hormone methyl jasmonate (MJ) was not influenced by whether a neighboring conspecific competitor in the same pot was MJ-induced or not. They suggested that MJ-treated plants might use limited nitrogen more efficiently in seed production by down-regulating photosynthetic proteins that are produced in excess of that which is required for growth. A similar effect may have caused costs of herbivore induction not to increase in the competitive environment in our study. In the wild parsnip (Pastinaca sativa) system, wound-induced furanocoumarins were detected under conditions of limited nutrients and shade, even when resources severely restricted growth; however, constitutive levels of furanocoumarins were significantly reduced under these conditions (Berenbaum and Zangerl 1999, and references therein). Thus, results to date from studies that have investigated the effects of stressful conditions on defense costs continue to be mixed, but hypotheses are beginning to form to explain the various patterns that are emerging. We conducted several experiments to test hypotheses concerning that absence of apparent costs in the competitive environment.

To understand what factors rendered costs of constitutive defenses undetectable when $B$. rapa was grown with a competitor, we evaluated four possibilities: (1) Competition reduced exponential growth rates to the extent that growth rate reduction was undetectable. (2) Competition reduced growth rates in a general fashion such that growth rates were low even in lines selected for low levels of secondary metabolites. (3) Limited resources associated with competition reduced defense production. (4) Glucosinolates and myrosinase also function as allelopathic agents, such that allelopathic benefits outweighed costs.

Our evidence does not support the hypotheses 1 to 3 that negative effects of Lolium on B. rapa growth or defense production explain reduced defense costs under competition. First, although costs associated with genetic variation in constitutive defenses were not detected in the competitive environment, we were able to detect costs associated with induced defenses at the same level of competition (Fig. 2), so that even at the low growth rates caused by competition, induced defense costs were detectable. Second, constitutive defense costs were not detected even when the strength of competition was lower. In the activated carbon experiment Lolium was planted at half the density as our original competition experiment; in the controls without carbon, growth rates of $B$. rapa were consequently twice as high and yet costs were still not detectable. Third, reducing nutrient availability did not differentially affect growth rates of these lines (Table 2). However, our nutrient supply treatments only decreased growth rates a maximum of $21 \%$, and contrary to our expectations, there were no main effects of nutrient supply on secondary metabolite concentrations. More severe reductions of nutrients might have produced different results.

Results from several direct tests suggest that the breakdown products of the myrosinase-glucosinolate reaction for chemical defense against herbivores may also be allelopathic to neighboring plants (hypothesis 4). First, exogenous glucosinolates plus myrosinase resulted in shorter roots for Lolium as glucosinolate concentration increased, while glucosinolates or glucosinolates plus heat-denatured myrosinase did not have the same effect (Fig. 3). Second, interactions between germinating seeds without nutrients still produced reciprocal negative interactions between $B$. rapa and Lolium (Fig. 4), and seeds from the line with high concentrations of both myrosinase and glucosinolates had the greatest negative affect on Lolium growth (Tables 3 and 4). Finally, we had suggestive nonsignificant evidence of restored costs in the presence of activated carbon, which can reduce allelopathic effects (Mahall and Callaway 1991, 1992). Thus, none of the experiments involving nutrient supply and weak competition supported the hypotheses (1-3) that the lack of defense costs in competitive environments was due to limited resources. Instead other experiments supported the hypothesis (4) that the breakdown products of the glucosinolate-myrosinase reaction appeared to function as allelopathic agents, which may benefit $B$. rapa plants in competition, thereby reducing costs of chemical defense.

In further support of the allelopathy hypothesis, members of the Brassicaceae have frequently been cited as being potentially allelopathic (Chew 1988), and a few studies have investigated the potential allelopathic effects of glucosinolates-myrosinase defense physiology. For instance, in annual grasslands in southern California, Bell and Muller (1973) noticed the absence of weedy grass species in areas dominated by Brassica nigra. They found that extracts of the volatile mustard oil allyl isothiocyanate from B. nigra leaves 
suppressed germination of grass seeds (Bromus rigi$d u s$ ) by atmospheric contact, but the effect was reduced in soil. Allyl isothiocyanate is a breakdown product of the glucosinolate-myrosinase reaction. Choesin and Boerner (1991) found that allyl isothiocyanates were released into the soil around plants of Brassica napus in a greenhouse, and that "mutant" B. napus plants secreted $61 \%$ less allyl isothiocyanate into soil than the wild type. However, they found no differences between the effects of wild type and mutant plants in intra- or interspecific (Medicago sativa) interactions. Angelini et al. (1998) found that hydrolysis products of glucosinolates isolated from ripe seeds of Crambe abyssinica, Eruca saliva, and Raphanus sativus inhibited seed germination of three weeds: Chenopodium album, Portulaca oleracea, and Echinochloa crus-galli, even at low concentrations. Our evidence from several experiments suggests that artificial selection on glucosinolates and myrosinase in foliage changed the levels of the breakdown products that exude from roots; however, we did not measure root exudates in this study. In contrast, herbivore induction of these secondary metabolites in shoots did not appear to change allelopathic effects of roots; i.e., we did not find a significant change in the magnitude of costs of induction among competition treatments (Fig. 2), suggesting that there were no allelopathic benefits from herbivore-induced changes in defenses. Our mass selection protocol may have resulted in systemic changes in secondary metabolite concentrations, whereas induction may have been localized.

Another set of explanations for the lack of increased costs under competition involves possible allelopathic effects of Lolium on B. rapa. The apparent allelopathic effects of Lolium on B. rapa (Fig. 4) could have decreased secondary metabolite production in the $B$. rapa line bred for high production, or differentially decreased growth in the line selected for low concentrations. These hypotheses are worthy of further studies and could have some effects in addition to the apparent allelopathic benefits of the glucosinolate-myrosinase system in Brassica. In total then, the negative reciprocal effects between Lolium and B. rapa involved limited resources and allelopathy. We have additional evidence (D. H. Siemens and M. Bates, unpublished manuscript) that the negative effects of Lolium on B. rapa also include effects independent of allelopathy (i.e., resource competition). This is from the result that $\mathrm{Lol}$ ium has negative effects on the growth of $B$. rapa when allelopathic effects are essentially eliminated by activated carbon $\left(F_{1,29}=13.00, P=0.001\right)$, while activated carbon had no effect on $B$. rapa performance when grown alone $\left(F_{3.59}=0.65, P=0.352\right)$.

Herms and Mattson (1992) were instrumental in incorporating plant competition into plant defense theory in their paper on the growth differentiation balance hypothesis (GDBH). The GDBH and similar hypotheses predict that plants can evolve to "grow or defend" by either investing resources in defense against herbivory and growing more slowly or investing in growth to outcompete neighbors but forgo defense against herbivores and pathogens. This prediction is based on a fundamental physiological trade-off between growth and differentiation. The empirical evidence for the "grow or defend" theory is based on the growth responses of plants when they are grown alone; however, in nature plants grow with neighbors. From our initial results suggesting that allelopathic benefits may have masked costs in the competitive environment, we investigated the potential for constitutive and induced defense chemicals to have more than one function, which could allow plants to "grow and defend." As Herms and Mattson (1992:306) acknowledged, growand-defend might be possible because of the dual function that some secondary metabolites might have in defense against herbivores and in allelopathic interactions between plants. Indeed, secondary metabolites may have multiple functions (Siegler and Price 1976, Haslam 1986). In the case where interactions involve specialist herbivores that have overcome glucosinolates, the role of glucosinolates as allelopathic agents may help explain the evolution of high glucosinolate levels even in the presence of a preponderance of specialist herbivores. Thus, the dilemma instead may be in conflicts created by secondary metabolites with multiple functions.

\section{ACKNOWLEDGMENTS}

Supported by USDA postdoctoral grant 93-37302-9572 to D. H. Siemens, by NSF grants BSR 9021451 and DEB9527725 to T. Mitchell-Olds, and by the Max-PlanckGesellschaft. We thank the Western Montana Agricultural Research Station and Teller Wildlife Refuge for use of land.

\section{Literature Cited}

Agrawal, A. A., and R. Karban. 1999. Why induced defenses may be favored over constitutive strategies in plants. Pages 45-61 in R. Tollrian and C. D. Harvell, editors. The ecology and evolution of inducible defenses. Princeton Press, Princeton, New Jersey, USA.

Angelini, L., L. Lazzeri, S. Galletti, A. Cozzani, M. Macchia, and S. Palmieri. 1998. Antigerminative activity of three glucosinolate-derived products generated by myrosinase hydrolysis. Seed Science and Technology 26:771-779.

Baldwin, I. T. 1998. Jasmonate-induced responses are costly but benefit plants under attack in native populations. Proceedings of the National Academy of Sciences, USA 95: 8113-8118.

Barker, H. R., and B. M. Barker. 1984. Multivariate analysis of variance (MANCOVA): a practical guide to its use in scientific decision making. University of Alabama Press, Tuscaloosa, Alabama, USA.

Bazzaz, F. A., and J. Grace. 1997. Plant resource allocation. Academic Press, San Diego, California, USA.

Bell, D. T., and C. H. Muller. 1973. Dominance of California annual grasslands by Brassica nigra. American Naturalist 90:277-299.

Berenbaum, M. R., and A. R. Zangerl. 1992. Quantification of chemical coevolution. Pages $69-87$ in R. S. Fritz and E. L. Simms, editors. Plant resistance to herbivores and pathogens: ecology, evolution, and genetics. Princeton Press, Princeton, New Jersey, USA.

Berenbaum, M. R., and A. R. Zangerl. 1999. Coping with 
live as a menu option: inducible defenses of the wild parsnip. Pages 10-32 in R. Tollrian and C. D Harvell, editors. The ecology and evolution of inducible defenses. Princeton Press, Princeton, New Jersey, USA.

Bergelson, J. 1994a. The effects of genotype and the environment on costs of resistance in lettuce. American Naturalist 143:349-359.

Bergelson, J. 1994b. Changes in fecundity do not predict invasiveness: a model study of transgenic plants. Ecology 75:249-252.

Bergelson, J., and C. B. Purrington. 1996. Surveying patterns in the cost of resistance in plants. American Naturalist 148: 536-588.

Bergelson, J., C. B. Purrington, C. J. Palm, and J. C. LopezGutierrez. 1996. Costs of resistance: a test using transgenic Arabidopsis thaliana. Proceedings of the Royal Society of London B 263:1659-1663.

Bodnaryk, R. P., and R. J. Lamb. 1991. Influence of seed size in canola, Brassica napus L., and mustard, Sinapis alba L., on seedling resistance against flea beetles, Phyllotreta cruciferae (Goeze). Canadian Journal of Plant Science 71: 397-404.

Bryant, J. P., F. S. Chapin, III, and D. R. Klein. 1983. Carbon/ nutrient balance of boreal plants in relation to vertebrate herbivory. Oikos 40:357-368.

Cheremisinoff, P. N., and F. Ellerbusch. 1978. Carbon adsorption handbook. Ann Arbor Science, Ann Arbor, Michigan, USA.

Chew, F. S. 1988. Searching for defensive chemistry in the Cruciferae, or, do glucosinolates always control interactions of Cruciferae with their potential herbivores and symbionts? No! Pages 81-112 in K. A. Spencer, editor. Chemical mediation of coevolution. Academic Press, New York, New York, USA.

Choesin, D. N., and R. E. J. Boerner. 1991. Allyl isothiocyanate release and the allelopathic potential of Brassica napus (Brassicaceae). American Journal of Botany 78: 1083-1090.

Falconer, D. S. 1989. Introduction to quantitative genetics. Third edition. Wiley, New York, New York, USA.

Gershenzon, J. 1984. Changes in the levels of plant secondary metabolites under water and nutrient stress. Recent Advances in Phytochemistry 18:273-320.

Harcourt, D. G. 1957. Biology of the diamondback moth, Plutella maculipennis (Curt.) (Lepidoptera: Plutellidae), in Eastern Ontario. II. Life-history, behavior, and host relationships. Canadian Entomologist 89:554-564.

Harvell, C. D., and R. Tollrian. 1999. Why inducible defenses? Pages 3-9 in R. Tollrian and C. D. Harvell, editors. The ecology and evolution of inducible defenses. Princeton University Press, Princeton, New Jersey, USA.

Haslam, E. 1986. Secondary metabolism-fact or fiction. Natural Products Reports 3:217-249.

Heaney, R. K., and G. R. Fenwick. 1981. A micro-column method for the rapid determination of total glucosinolate content of cruciferous material. Zeitschrift für Pflanzenzüchtung 87:89-95.

Herms, D. A., and W. J. Mattson. 1992. The dilemma of plants: to grow or defend. Quarterly Review of Biology 67:283-335.

Hill, W. G., and A. Caballero. 1992. Artificial selection experiments. Annual Review of Ecology and Systematics 23: 287-310.

Inderjit, and R. Del Moral. 1997. Is separating resource competition from allelopathy realistic? Botanical Review 63 : 221-230.

Lamb, R. J. 1989. Entomology of oilseed Brassica crops. Annual Review of Entomology 34:211-229.

Larsen, P. O. 1981. Glucosinolates. Pages 501-525 in P. K. Stumpf and E. E. Conn, editors. The biochemistry of plants.
Volume seven. Academic Press, New York, New York, USA.

Lewontin, R. C. 1974. The analysis of variance and the analysis of causes. American Journal of Human Genetics 26: 400-411.

Kahl, J., D. H. Siemens, R. J. Aerts, R. Gäbler, F. Kühnemann, C. A. Preston, and I. T. Baldwin. 2000. Herbivore-induced ethylene suppresses a direct defense but not an indirect defense against an adapted herbivore. Planta 210:336-342.

Karban, R., and I. T. Baldwin. 1997. Induced responses to herbivory. University of Chicago Press, Chicago, Illinois, USA.

Louda, S. M., and J. E. Rodman. 1983. Concentration of glucosinolates in relation to habitat and insect herbivory for the native crucifer Cardamine cordifolia. Biochemical Systematics and Ecology 11:199-207.

Mahall, B. E., and R. M. Callaway. 1991. Root communication among desert shrubs. Proceedings of the National Academy of Sciences 88:874-876.

Mahall, B. E., and R. M. Callaway. 1992. Root communication mechanisms and intracommunity distributions of two Mojave Desert shrubs. Ecology 73:2145-2151.

McKey, D. 1974. Adaptive patterns in alkaloid physiology. American Naturalist 108:305-320.

Miller, T. E. 1995. Evolution of Brassica rapa L. (Cruciferae) populations in intra- and interspecific competition. Evolution 49:1125-1133.

Mitchell-Olds, T., D. Siemens, and D. Pedersen. 1996. Physiology and costs of resistance to herbivory and disease in Brassica. Entomologia Experimentalis et Applicata 88: 231-237.

Pilson, D. 1993. Natural selection for resistance to three herbivores in Brassica campestris. Bulletin Ecological Society of America 74:394.

Poulton, J. E., and B. L. Moller. 1993. Glucosinolates. Pages 209-237 in J. P. Lea, editor. Methods in plant biochemistry. Volume 9. Academic Press, London, UK.

Purrington, C. B. 2000. Costs of resistance. Current Opinion in Plant Biology 3:305-308.

Purrington, C. B., and J. Bergelson. 1997. Fitness consequences of genetically engineered herbicide and antibiotic resistance in Arabidopsis thaliana. Genetics 145:807-814.

Purrington, C. B., and J. Bergelson. 1999. Exploring the physiological basis of costs of herbicide resistance in $\mathrm{Ar}$ abidopsis thaliana. American Naturalist 154:S81-S91.

Rask, L., E. Andréasson, B. Ekbom, S. Eriksson, B. Pontoppidan, and J. Meijer. 2000. Myrosinase: gene family evolution and herbivore defense in Brassicaceae. Plant Molecular Biology 42:93-113.

Rausher, M. 1996. Genetic analysis of coevolution between plants and their natural enemies. Trends in Genetics 12: 212-217.

Rhoades, D. F. 1979. Evolution of plant chemical defenses against herbivory. Pages 3-54 in G. A. Rosenthal and D. H. Janzen, editors. Herbivores: their interaction with secondary plant metabolites. Academic Press, New York, New York, USA.

Rice, W. R. 1989. Analyzing tables of statistical tests. Evolution 43:223-225.

SAS Institute. 1989. SAS/STAT user's guide, version six. Fourth edition. SAS Institute, Cary, North Carolina, USA. Shelton, A. M., R. J. Cooley, M. K. Kroening, W. T. Wilsey, and S. D. Eigenbrode. 1990. Comparative analysis of two rearing procedures for diamondback moth (Lepidoptera: Plutellidae). Journal of Entomological Science 26:17-26.

Siegler, D., and P. W. Price. 1976. Secondary compounds in plants: primary functions. American Naturalist 110:101105.

Siemens, D. H., and T. Mitchell-Olds. 1996. Glucosinolates and herbivory by specialists (Coleoptera: Chrysomelidae; 
Lepidoptera: Plutellidae): consequences of concentration and induced resistance. Environmental Entomology 25: 1344-2353.

Siemens, D. H., and T. Mitchell-Olds. 1998. Evolution of plant defense mechanisms: tests of theory on induced defenses. Ecology 79:632-646.

Simms, E. L. 1992. Costs of plant resistance to herbivory. Pages 392-425 in R. S. Fritz and E. L. Simms, editors. Plant resistance to herbivores and pathogens: ecology, evolution, and genetics. University of Chicago Press, Chicago, Illinois, USA.

Simms, E. L., and M. D. Rausher. 1992. Uses of quantitative genetics for studying the evolution of plant resistance. Pages 42-68 in R. S. Fritz and E. L. Simms, editors. Plant resistance to herbivores and pathogens. University of Chicago Press, Chicago, Illinois, USA.

Snedecor, G. W., and W. G. Cochran. 1980. Statistical methods. Seventh edition. Iowa State University Press, Ames, Iowa, USA.

Steel, R. G. D., and J. H. Torrie. 1980. Principles and procedures of statistics: a biometrical approach. Second edition. McGraw-Hill, New York, New York, USA.

Stotz, H. U., J. Kroymann, and T. Mitchell-Olds. 1999. Plantinsect interactions. Current opinion in Plant Biology 2:268272.

Stowe, K. A. 1998. Experimental evolution of resistance in Brassica rapa: correlated response of tolerance in lines selected for glucosinolate content. Evolution 52:703-712.

Strauss, S. Y., D. H. Siemens, M. B. Decher, and T. MitchellOlds. 1999. Ecological costs of plant resistance to herbivores in the currency of pollination. Evolution 53:11051113
Thomas, P. 1984. Canola growers manual. Canola Council of Canada, Winnipeg, Canada.

van Dam, N. M., and I. T. Baldwin. 1998. Costs of jasmonateinduced responses in plants competing for limited resources. Ecology Letters 1:30-33.

Wardle, D. A., G. M. Barker, K. I. Bonner, and K. S. Nicholson. 1998. Can comparative approaches based on plant ecophysiological traits predict the nature of biotic interactions and individual plant species effects in ecosystems. Journal of Ecology 86:405-420.

Waterman, P. G., and S. Mole. 1989. Extrinsic factors influencing production of secondary metabolites in plants. Pages 107-134 in E. A. Bernays, editor. Insect-plant interactions. CRC Press, Boca Raton, Florida, USA.

Williams, M. M. II., N. Jordan, and C. Yerkes. 1995. The fitness cost of triazine resistance in jimsonweed (Datura stramonium L.). American Midland Naturalist 133:131137.

Williamson, G. B. 1990. Allelopathy, Koch's postulates, and the neck riddle. Pages 143-162 in J. B. Grace and D. Tilman, editors. Perspectives on plant competition. Academic Press, San Diego, California, USA.

Wolfson, J. L. 1982. Developmental responses of Pieris rapae and Spodoptera eridania to environmentally induced variation in Brassica nigra. Environmental Entomology 11: 207-213.

Zangerl, A. R., and F. A. Bazzaz. 1992. Theory and pattern in plant defense allocation. Pages 363-391 in R. S. Fritz and E. L. Simms, editors. Plant resistance to herbivores and pathogens: ecology, evolution, and genetics. University of Chicago Press, Chicago, Illinois, USA. 